\title{
Short communication: Drug residues in goat milk after prophylactic use of antibiotics in intravaginal sponges for estrus synchronization
}

\author{
T. Romero, ${ }^{\star 1}$ J. Balado,† R. L. Althaus, $\ddagger$ M. C. Beltrán, ${ }^{*}$ and M. P. Molina* \\ *Instituto de Ciencia y Tecnología Animal, Universitat Politècnica de València, 46022 Valencia, Spain \\ †Granja Experimental Diputación Provincial de Castellón, Castellón, Spain \\ †Cátedra de Biofísica. Facultad de Ciencias Veterinarias, Universidad Nacional del Litoral, 3080 Esperanza, Argentina
}

\begin{abstract}
The aim of this study was to determine whether the prophylactic use of antibiotics in intravaginal sponges used for estrus synchronization in goats may result in the presence of inhibitors in milk and, therefore, of positive results by microbial screening tests. Ninetyeight Murciano-Granadina goats were used, divided into 7 groups of 14 animals. Intravaginal sponges were placed in 6 groups using 2 concentrations of 3 different antibiotics: doxycycline, oxytetracycline, and sulfathiazole-framycetin. The sponges of the control group were placed without antibiotics. Milk samples were collected daily until $7 \mathrm{~d}$ posttreatment and analyzed using $3 \mathrm{mi}-$ crobial tests. Positive samples were retested by specific receptor-binding assays to confirm the positive results. Vaginal status was evaluated by visual assessment of the external aspect of the sponges after removal. The microbial test response was not affected by either day posttreatment or dose of antibiotic used, except for oxytetracycline at the higher concentration. Moreover, no positive results were obtained using receptor-binding assays, suggesting that residues, if present in milk, did not exceed the regulatory (safety) levels established for these drugs. The occurrence of soiled sponges was higher in the control group. With respect to the dose of antibiotics used, no significant differences were found for the lower dose administered. However, a significant increase in the percentage of clean sponges was observed for the higher dose of doxycycline. We conclude that the prophylactic use of low doses of doxycycline, oxytetracycline, or sulfathiazole in intravaginal sponges used for synchronization of estrus helps to reduce clinical vaginitis in dairy goats and does not seem to be the cause of positive results in microbial inhibitor tests used to detect antibiotics in goat milk.
\end{abstract}

Received August 3, 2015.

Accepted September 19, 2015.

${ }^{1}$ Corresponding author: tarorue@upvnet.upv.es
Key words: goat milk, intravaginal sponge, antibiotic screening methods

\section{Short Communication}

Intravaginal sponges impregnated with progesterone or synthetic progestogens during 6 to $16 \mathrm{~d}$ before AI are typically used for estrus synchronization in goats (Menchaca and Rubianes, 2004; Rowe et al., 2009). However, this practice is related to the occurrence of clinical vaginitis in goats (Motlomelo et al., 2002; Penna et al., 2013), which could negatively affect fertility rates on farms (Scudamore, 1988).

To avoid these negative effects, some authors recommend sprinkling the sponges with antibiotics before their insertion in the vagina (Guerra et al., 2002; Suárez et al., 2006; Gatti et al., 2011), with oxytetracycline being the drug commonly used for this purpose in practice (Manes et al., 2013). Such prophylactic use of antibiotics in the placement of intravaginal sponges is an unregulated management practice for which there are no approved recommendations with regard to the dose and withdrawal period required to avoid the presence of drug residues in milk. In goats, estrus synchronization using intravaginal sponges takes place during lactation and, therefore, the inclusion of antibiotics on sponges may pose a risk of contamination of the milk. Some researchers have found antibiotic residues in cow milk 24 to $48 \mathrm{~h}$ after intrauterine administration of suppositories, infusions, and tablets of penicillin, streptomycin, and tetracycline (Miller and Bergt, 1976; Black et al., 1979; Bishop et al., 1984). In ewes, drug residues in milk after the inclusion of intravaginal sponges impregnated with benzylpenicillin procaine were evaluated by Berruga et al. (2008) by using different microbial inhibitor tests for screening antibiotics. Positive and inconclusive results were obtained at the time of the first milking, and occasionally later, due to the presence of drug residues in milk. In dairy goats, related information is rather limited.

Microbial inhibitor tests are widely used for screening for antibiotics in milk above maximum residue 
limits (MRL) established by legislation (European Union, 2010). The performance of these screening tests (specificity and detection capability) allows the detection of a large number of substances in milk at or below the MRL to guarantee the safety of milk and related products.

Thus, the aim of this study was to evaluate whether the prophylactic use of antibiotics on intravaginal sponges used in the synchronization of estrus in goats may explain the presence of inhibitors in milk and, therefore, of positive results in the microbial screening tests.

Experimental animal procedures were approved by the Ethics Committee of Universitat Politècnica de València (UPV, Valencia, Spain). Ninety-eight Murciano-Granadina goats in the fourth month of lactation, from the herd of Diputación de Castellón de la Plana (Ares del Maestrat, Spain) were used. The animals were healthy and did not receive any drug treatment before the experiment.

Goats were randomly divided into 7 groups of 14 animals each. A polyurethane sponge containing $30 \mathrm{mg}$ of flugestone acetate (Sincropart, Ceva Salud Animal, Barcelona, Spain) was inserted into the vagina for an 11-d period. Before insertion, the sponges were impregnated with 2 concentrations of 3 veterinary drugs usually applied in dairy goats: doxycycline (Hipradoxi, Laboratorios Hipra, S.A., Gerona, Spain), oxytetracycline (Terramycin, Pfizer S.L.U., Madrid, Spain), and sulfathiazole-framycetin (96\%/4\%; Framicas, Laboratorios Ovejero S.A., León, Spain). Consistent with veterinary practice, antibiotics were added into a bag containing 25 sponges and mixed by shaking. In the control group, the sponges did not contain any antibiotic. Two doses of antibiotics were used: dose 1 was equivalent to $1 \mathrm{~g}$ of commercial product corresponding to a concentration of $100 \mathrm{mg}$ (active agent) of doxycycline, $550 \mathrm{mg}$ of oxytetracycline, or $960 \mathrm{mg}$ of sulfathiazole; dose 2 was equivalent to 2 g (i.e., twice the amount of active compound of dose 1 ).

According to the estrus synchronization protocol of hormonal treatment, on d 9 after the placement of the intravaginal sponge, an i.m. administration of $300 \mathrm{IU}$ of equine chorionic gonadotropin (Sincropart PMSG, Ceva Salud Animal, Barcelona, Spain) and $0.5 \mathrm{~mL}$ of Enzaprost (synthetic analog of $\mathrm{PGF}_{2 \alpha}$, Ceva Salud Animal) was applied. Vaginal status was evaluated through visual assessment of the sponge's external aspect after removal. Sponges were classified as follows: $0=$ clean sponge (without bloody, purulent or foul-smelling discharges), 1 = soiled sponge (presence of bloody secretions and vaginal mucus but no abnormal odor), and $2=$ very soiled sponge (presence of bloody secretions, high quantity of vaginal mucus, and foul odor).
The animals were milked once a day $(0700 \mathrm{~h})$ in a milking parlor. For $7 \mathrm{~d}$ after sponge insertion, individual goat milk samples $(100 \mathrm{~mL})$ were collected and transported under refrigeration $\left(<10^{\circ} \mathrm{C}\right)$ to the laboratories of the Universitat Politècnica de València (Valencia, Spain).

Milk samples were analyzed in triplicate by using 3 microbial inhibitor tests: BRT MRL (AiM Analytik in MilchProduktions-und Vertriebs-GmbH, Munich, Germany), Delvotest SP-NT MCS (DSM Food Specialties, Delft, the Netherlands), and Eclipse 100 (Zeulab S.L., Zaragoza, Spain) according to each manufacturer's instructions. In all cases, negative (antimicrobialfree milk) and positive (milk spiked with $4 \mu \mathrm{g} / \mathrm{kg}$ of benzylpenicillin) controls were included in each test. Interpretation of the test results was carried out independently by 3 trained technicians by visually assessing the color change after incubation and classifying milk samples as positive (blue) or negative (yellow). Positive samples were retested by specific receptor-binding assays for tetracycline (SNAP Tetracycline test, Idexx Laboratories, Westbrook, ME) and for sulfonamides (Sulfasensor test, Unisensor, Liege, Belgium) following each manufacturer's instructions. The test results were classified as positive or negative by instrumental readers (SNAP shot reader, Idexx Laboratories and Readsensor, Unisensor).

The detection limits (DL) of microbial inhibitor tests for doxycycline, oxytetracycline, and sulfathiazole were calculated according to the International Dairy Federation recommendations (IDF, 2003) and are summarized in Table 1 . The DL of the receptor-binding assays provided by the manufacturers were also included (Table1).

A logistic regression model was applied to evaluate both the effect of the dose of antibiotic administered and the days after treatment on the occurrence of positive outcomes in the microbial screening tests:

$$
\begin{gathered}
\mathrm{L}_{\mathrm{ijk}}=\operatorname{Logit}\left[\mathrm{P}_{\mathrm{ijk}}\right]+\beta_{0}+\beta_{1}[\mathrm{PD}]_{\mathrm{i}}+\beta_{2} \mathrm{D} 1 \\
+\beta_{3} \mathrm{D} 2+\varepsilon_{\mathrm{ijk}},
\end{gathered}
$$

where $\mathrm{L}_{\mathrm{ijk}}=\operatorname{Logit}$ model; $\left[\mathrm{P}_{\mathrm{ijk}}\right]=$ probability for the response category (positive or negative); $\beta_{0}=$ intercept; $\beta_{1}, \beta_{2}, \beta_{3}=$ parameters estimated for the model; $[\mathrm{PD}]_{\mathrm{i}}$ $=$ effect of the days posttreatment $(\mathrm{n}=7) ; \mathrm{D} 1$ and $\mathrm{D} 2$ $=$ effect of dose 1 and dose 2 , respectively, in dummy variable (without antibiotic: $\mathrm{D} 1=0$ and $\mathrm{D} 2=0$; dose 1: $\mathrm{D} 1=1$ and $\mathrm{D} 2=0$; dose $2: \mathrm{D} 1=0$ and $\mathrm{D} 2=1$ ); and $\varepsilon_{\mathrm{ijk}}=$ residual error.

To evaluate the status of the sponges as an indicator of the antibiotic's effectiveness to prevent clinical vaginitis, the $\chi^{2}$ test was applied. Statistical analyses 
Table 1. Detection limits $(\mu \mathrm{g} / \mathrm{kg})$ of microbial inhibitor tests and receptor-binding assays for the detection of antimicrobials in goat milk

\begin{tabular}{|c|c|c|c|}
\hline \multirow[b]{2}{*}{ Method } & \multicolumn{3}{|c|}{ Antimicrobial $^{1}$} \\
\hline & Doxycycline & Oxytetracycline & Sulfathiazole \\
\hline \multicolumn{4}{|l|}{ Microbial inhibitor test ${ }^{2}$} \\
\hline BRT MRL & 135 & 124 & 48 \\
\hline Delvotest SP-NT MCS & 106 & 297 & 39 \\
\hline Eclipse 100 & 113 & 134 & 47 \\
\hline \multicolumn{4}{|l|}{ Receptor-binding assay ${ }^{3}$} \\
\hline SNAP Tetracycline Test & $30^{4}$ & $\geq 50$ & - \\
\hline Sulfasensor test & - & - & $5-8$ \\
\hline
\end{tabular}

${ }^{1}$ Maximum residue limit (MRL) for doxycycline was not established, because it cannot be used in animals from which milk is produced for human consumption; MRL for oxytetracycline and sulfathiazole $=100 \mu \mathrm{g} / \mathrm{kg}$. ${ }^{2}$ BRT MRL from AiM Analytik in MilchProduktions-und Vertriebs-GmbH (Munich, Germany); Delvotest SPNT MCS from DSM Food Specialties (Delft, the Netherlands); Eclipse 100 from Zeulab S.L. (Zaragoza, Spain). ${ }^{3}$ SNAP Tetracycline Test from Idexx Laboratories (Westbrook, ME); Sulfasensor test from Unisensor (Liege, Belgium); data provided by manufacturers.

${ }^{4} \mathrm{~A}$ concentration of $30 \mu \mathrm{g} / \mathrm{kg}$ of doxycycline, SNAP Tetracycline tests presented $100 \%$ positive results.

were performed using SAS software (version 9.2. 2001; SAS Institute Inc., Cary, NC).

Table 2 shows the positive results obtained for the microbial inhibitor tests in the first week after treatment. In general, the microbial test response was unaffected by the dose of antibiotic added to intravaginal sponges $(P>0.05)$. Thus, the occurrence of positive results in milk from goats belonging to the control group was similar to that obtained for milk from goats treated with antibiotics. Only for the higher dose of oxytetracycline $(2 \mathrm{~g} / 25$ sponges $)$ was a significant increase $(P<0.05)$ of positive results in the BRT MRL test observed. No significant differences were found $(P$ $>0.05)$ throughout the $7 \mathrm{~d}$ posttreatment. The results obtained herein differ from those reported by Berruga et al. (2008), who used intravaginal sponges impregnated with a drug that combines benzylpenicillin procaine and DH-streptomycin in sheep; that study reported the highest occurrence of positive results in the first milking after treatment.

No positive results were obtained when milk samples were retested by specific receptor-binding assays, suggesting that drug residues, if present in milk, were below the DL of these tests, and did not exceed the MRL established in the legislation. Therefore, positive outcomes in the microbial inhibitor tests used in the current study might be related to the performance of these nonspecific tests, which can be affected by several factors related to milk composition, leading to noncompliant results in milk free of antibiotics. The percentage of positive results obtained in this study is similar to the false-positive rate reported by Beltrán et al. (2015) for 2 of the microbial tests using individual goat milk samples (Delvotest SP-NT MCS: 3.1\%; Eclipse 100:
$0.6 \%)$; the BRT MRL test in the current study had a higher percentage of positive results than that reported by those authors (6.1 vs. $1.4 \%$ ).

Regarding vaginal status evaluated through the presence of bloody, purulent, or foul-smelling discharges into sponges after removal (Figure 1), the occurrence of soiled sponges in the control group was higher $(P$ $<0.05)$ than that obtained in the groups treated with antimicrobials. In terms of the dose of antibiotics used, no significant differences were obtained for the lower dose administered, showing similar percentages for all 3 antimicrobials $(P>0.05)$. However, for the higher dose, a significant increase in the percentage of clean sponges was observed, with doxycycline (Hipradoxi) being the most effective drug $(P<0.05)$. These results are in agreement with those reported by Manes et al. (2013) and Guerra et al. (2002), who indicated that the inclusion of antibiotics in sponges prevented vaginal infections in goats caused by the use of intravaginal sponges.

Prophylactic use of low amounts of doxycycline, oxytetracycline, or sulfathiazole in the intravaginal sponges used for synchronization of estrus helps to reduce the incidence of clinical vaginitis in dairy goats and does not seem to be the cause of positive results in microbial inhibitor tests used to detect antibiotics in goat milk.

\section{ACKNOWLEDGMENTS}

This work is part of the AGL-2009-11524 Project funded by the Spanish Ministry of Science and Innovation (Madrid, Spain). The authors are grateful to the Diputación de Castellón and UNISENSOR S.A (Angleur, Belgium) for their support. 


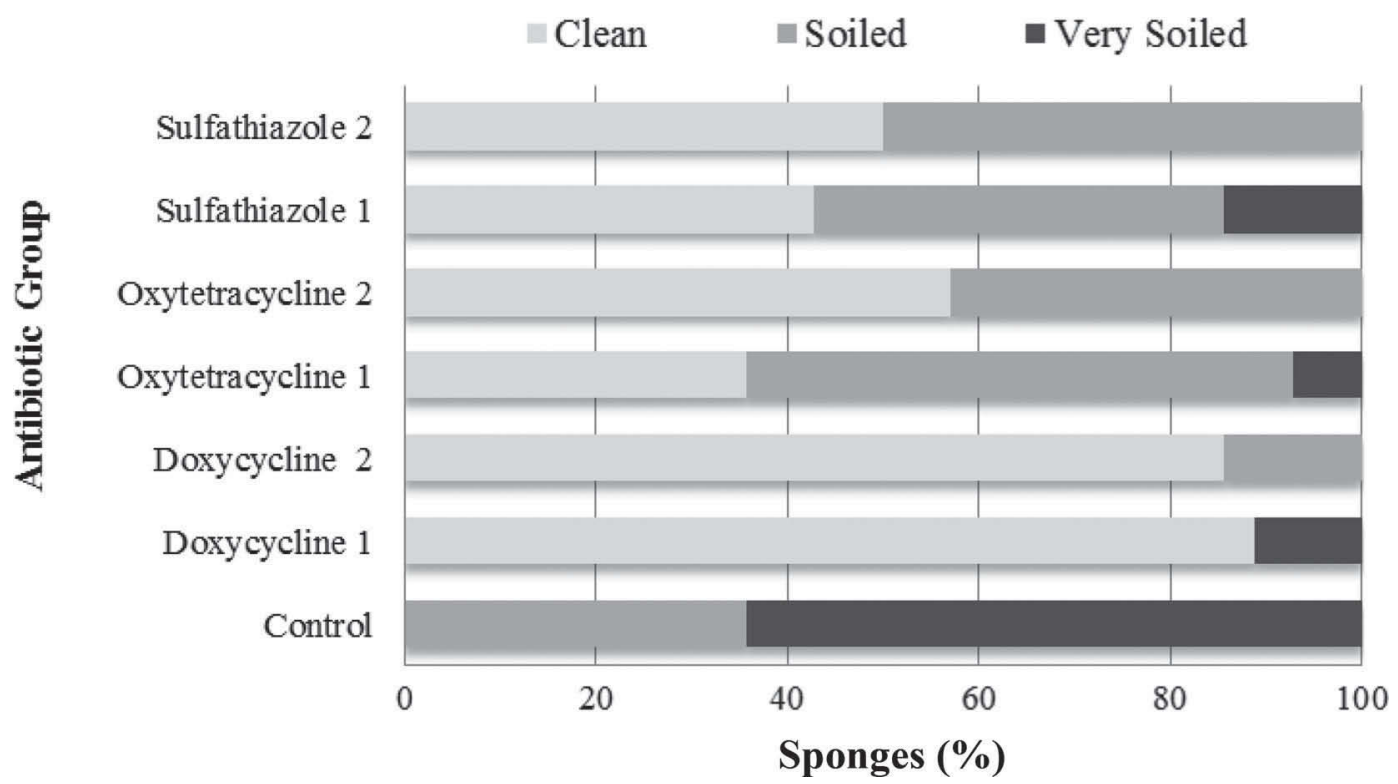

Figure 1. Visual classification of sponge status after removal according to the effectiveness of the different antibiotics and doses used. Dose 1 (e.g., sulfathiazole 1) was equivalent to $1 \mathrm{~g}$ of commercial product, corresponding to a concentration of $100 \mathrm{mg}$ (active agent) of doxycycline, $550 \mathrm{mg}$ of oxytetracycline, or $960 \mathrm{mg}$ of sulfathiazole; dose 2 (e.g., sulfathiazole 2) was equivalent to $2 \mathrm{~g}$ of commercial product.

Table 2. Positive results by microbial inhibitor tests during the first week after intravaginal sponge insertion in dairy goats

\begin{tabular}{|c|c|c|c|c|c|c|c|c|c|}
\hline \multirow[b]{2}{*}{ Test $^{1}$ and treatment } & \multirow[b]{2}{*}{$\operatorname{Dose}^{2}$} & \multicolumn{7}{|c|}{ Days after sponge insertion } & \multirow{2}{*}{$\begin{array}{c}\text { Total } \\
(\%)\end{array}$} \\
\hline & & 1 & 2 & 3 & 4 & 5 & 6 & 7 & \\
\hline \multicolumn{10}{|l|}{ BRT MRL } \\
\hline Control & & 0 & 2 & 1 & 1 & 2 & 0 & 0 & 6.1 \\
\hline \multirow[t]{2}{*}{ Doxycycline } & Dose 1 & 0 & 3 & 1 & 0 & 1 & 2 & 0 & 7.1 \\
\hline & Dose 2 & 0 & 2 & 2 & 0 & 1 & 2 & 0 & 7.1 \\
\hline \multirow[t]{2}{*}{ Oxytetracycline } & Dose 1 & 1 & 1 & 0 & 4 & 0 & 0 & 0 & 6.1 \\
\hline & Dose 2 & 3 & 2 & 3 & 3 & 3 & 0 & 0 & 14.3 \\
\hline \multirow[t]{2}{*}{ Sulfathiazole } & Dose 1 & 0 & 1 & 1 & 1 & 1 & 0 & 0 & 4.1 \\
\hline & Dose 2 & 1 & 1 & 0 & 0 & 0 & 0 & 1 & 3.1 \\
\hline \multicolumn{10}{|l|}{ Delvotest SP-NT MCS } \\
\hline Control & & 0 & 0 & 0 & 0 & 1 & 0 & 0 & 1 \\
\hline \multirow[t]{2}{*}{ Doxycycline } & Dose 1 & 0 & 0 & 0 & 0 & 0 & 0 & 0 & 0 \\
\hline & Dose 2 & 0 & 0 & 0 & 1 & 0 & 0 & 0 & 1 \\
\hline \multirow[t]{2}{*}{ Oxytetracycline } & Dose 1 & 0 & 1 & 0 & 0 & 0 & 0 & 0 & 1 \\
\hline & Dose 2 & 0 & 0 & 1 & 0 & 0 & 2 & 0 & 3.1 \\
\hline \multirow{2}{*}{ Sulfathiazole } & Dose 1 & 0 & 0 & 1 & 0 & 0 & 0 & 0 & 1 \\
\hline & Dose 2 & 0 & 1 & 0 & 0 & 0 & 0 & 0 & 1 \\
\hline \multicolumn{10}{|l|}{ Eclipse 100} \\
\hline Control & & 0 & 0 & 1 & 0 & 0 & 0 & 0 & 1 \\
\hline \multirow[t]{2}{*}{ Doxycycline } & Dose 1 & 0 & 0 & 0 & 0 & 0 & 0 & 0 & 0 \\
\hline & Dose 2 & 0 & 0 & 0 & 0 & 0 & 0 & 0 & 0 \\
\hline \multirow[t]{2}{*}{ Oxytetracycline } & Dose 1 & 0 & 0 & 0 & 1 & 0 & 0 & 0 & 1 \\
\hline & Dose 2 & 0 & 0 & 0 & 1 & 0 & 0 & 0 & 1 \\
\hline \multirow[t]{2}{*}{ Sulfathiazole } & Dose 1 & 0 & 0 & 0 & 1 & 0 & 0 & 0 & 1 \\
\hline & Dose 2 & 0 & 0 & 0 & 0 & 0 & 0 & 0 & 0 \\
\hline
\end{tabular}

${ }^{1}$ BRT MRL from AiM Analytik in MilchProduktions-und Vertriebs-GmbH (Munich, Germany); Delvotest SPNT MCS from DSM Food Specialties (Delft, the Netherlands); Eclipse 100 from Zeulab S.L. (Zaragoza, Spain).

${ }^{2}$ Dose 1 was equivalent to $1 \mathrm{~g}$ of commercial product, corresponding to a concentration of $100 \mathrm{mg}$ (active agent) of doxycycline, $550 \mathrm{mg}$ of oxytetracycline, or $960 \mathrm{mg}$ of sulfathiazole; dose 2 was equivalent to $2 \mathrm{~g}$ of commercial product. 


\section{REFERENCES}

Beltrán, M. C., M. I. Berruga, A. Molina, R. L. Althaus, and M. P. Molina. 2015. Performance of the current microbial tests for screening antibiotic in sheep and goat milk. Int. Dairy J. 41:13-15.

Berruga, M. I., A. Rodriguez, R. Rubio, R. Gallego, and A. Molina. 2008. Short communication: Antibiotic residues in milk following the use of intravaginal sponges for estrus synchronization in dairy ewes. J. Dairy Sci. 91:3917-3921.

Bishop, J. R., A. B. Bodine, G. D. O'Dell, and J. J. Jazen. 1984. Retention data for antibiotics commonly used for bovine infections. J. Dairy Sci. 67:437-440.

Black, W. D., A. L. Mackay, P. A. Doing, and M. J. Claxton. 1979. A study of drugs residues in milk following intrauterine infusion of antibacterial drugs in lactating cows. Can. Vet. J. 20:354-357.

European Union. 2010. Commission Regulation (EU) No. 37/2010. On pharmacologically active substances and their classification regarding maximum residue limits in foodstuffs of animal origin. Off. J. L15:1-72.

Gatti, M., P. Zunino, and R. Ungerfeld. 2011. Changes in the aerobic vaginal mucous load after treatment with intravaginal sponges in anoestrous ewes: Effect of medroxiprogesterone acetate and antibiotic treatment use. Reprod. Domest. Anim. 46:205-208.

Guerra, M. M. P., R. A. Mota, F. C. C. Mergualhao, F. R. Lima, A. F. Souza, E. H. Melo, K. P. C. Silva, and P. C. Solares. 2002. Study of the microbial flora and evaluation of the effectiveness of Gentocin ${ }^{\circledR} 40 \mathrm{mg}$ in the prevention of vaginal infection in dairy goats submitted to estrous synchronization. Hora Vet. 22:13-17.

IDF (International Dairy Federation). 2003. Milk and milk productsGuidelines for a standardized description of microbial inhibitor tests. IDF Standard No. 183. Int. Dairy Fed., Brussels, Belgium.
Manes, J. M., A. Fiorentino, F. Hozbor, F. Paolicchi, R. Alberio, and R. Ungerfeld. 2013. Changes in the aerobic vaginal bacteria load and antimicrobial susceptibility after different oestrus synchronization treatments in goats. Anim. Prod. Sci. 53:555-559.

Menchaca, A., and E. Rubianes. 2004. New treatments associated with timed artificial insemination in small ruminants. Reprod. Fertil. Dev. 16:403-413.

Miller, G. E., and G. P. Bergt. 1976. Oxytetracycline in bovine plasma, milk, urine after intrauterine administration. J. Dairy Sci. 59:315-317.

Motlomelo, K. C., J. P. C. Greyling, and L. M. J. Schwalbach. 2002. Synchronisation of oestrus in goats: The use of different progestogen treatments. Small Rumin. Res. 45:45-49.

Penna, B., H. Libonati, A. Director, A. C. Sarzedas, G. Martins, F. Z. Brandão, J. Fonseca, and W. Lilenbaum. 2013. Progestin-impregnated intravaginal sponges for estrus induction and synchronozation influences on goats' vaginal flora and antimicrobial susceptibility. Anim. Reprod. Sci. 142:71-74.

Rowe, J. D., L. A. Tell, and D. C. Wagner. 2009. Animal safety report on intravaginal progesterone controlled internal drug releasing devices in sheep and goats. J. Vet. Pharmacol. Ther. 32:303-305.

Scudamore, C. L. 1988. Intravaginal sponge insertion technique. Vet. Rec. 123:554.

Suárez, G., P. Zunino, H. Carol, and R. Ungerfeld. 2006. Changes in the aerobic vaginal bacterial mucous load and assessment of the susceptibility to antibiotics after treatment with intravaginal sponges in anoestrous ewes. Small Rumin. Res. 63:39-43. 